\title{
GROSSETESTE Y LA TRANSMUTACIÓN DE LOS METALES
}

\author{
Celina A. Lértora Mendoza*
}

SINTESE - Na visão da ciência e da alquimia do século XIII, os metais não áureos são considerados degradações do ouro. Aceitando este ponto de partida, Robert Grosseteste julga possivel separar a ganga existente em tais metais, os quais, assim, se transformariam em ouro. Ao traçar normas para tais tentativas, ele se torna um inovador na metodologia científica.

\begin{abstract}
According to the conception of science and alchemy in the thirteenth century, not golden metals are considered as degradations of the gold. Assuming this hypothesis, Robert Grosseteste thinks that is possible to separate the impurities in those metals and so transmute them into gold. By the rules he gave for such attempts, he becomes an innovator in scientific methodology.
\end{abstract}

El sueño alquimista de transformar metales innobles en oro ha sido, desde una remota antigüedad, preocupación de muchos estudiosos y el resultado de innumerables intentos quedó atestiguado por la existencia de diversas obras herméticas sobre las pretendidas técnicas transformadoras. Durante el medioevo la alquimia atrajo la atención de los espíritos más sagaces, y por eso todos o casi todos los filósofos y científicos de la época se han ocupado, o al menos referido a ella. Si bien la "magna obra" tenía sin duda un sentido material y concreto, no faltaron tampoco los espiritualistas que buscaban analogías y simbolismos entre las etapas de la transmutación de los metales y el proceso perfectivo del alma humana.

En la medida en que la escuela oxoniense del s. XIII fue un gran centro receptor de la tradición grecolatina y árabe, recibió también un cuerpo de tratados esotéricos que conservó y estudió. Entre ellos, además de los pasajes aristotélicos referidos a la transmutación, dentro del corpus, y los tratados alquimistas árabes, merecen especial atención de los ingleses las obras árabes; Geber fue muy estimado, aunque sólo a través de algunas de las muchas obras que se le atribuyeron en el mundo árabe. Su teoría sobre el surgimiento de los metales por influjo planetario perduró en Europa hasta el s. XVII. Entre sus sucesores, Rhazes fue también estimado, y su obra quimica De aluminibus et salibus fue traducida en Toledo por Ge-

* CONICET, Buenos Aires.

\begin{tabular}{|l|l|l|l|l|l|} 
VERITAS & Porto Alegre & v. 41 & $n^{2} 163$ & Setembro 1996 & p. 423-434 \\
\hline
\end{tabular}


rardo de Cremona, en el s. XII. ${ }^{1}$ También el pseudo-aristotélico De proprietatibus elementorum (obra árabe de geología), el De mineralibus de Avicena (parte geológica del Kitab-al-Shifa) y las partes pertinentes del comentario averroista al corpus aristotelicum, fueron conocidos a principios del s. XIII por el trabajo de Gerardo, Alfredo de Sareshel (ambos del s. XII) y la escuela toledana del s. XIII respectivamente. ${ }^{2}$ La conexión entre la alquimia latina a partir del s. XII y sus antecedentes árabes es cada vez más clara. Tenemos el caso de Turba Philosophorum, anterior a la obra de Rhazes y al Corpus Jabirianum, que parece atacar a los alquimistas griegos y lucha por independizar la alquimia de la filosofia natural, aunque sus aspectos propiamente alquímicos provienen de la alquimia griega y en su conjunto se revela como un fuerte intento de introducir la alquimia en el Islam. ${ }^{3} \mathrm{El}$ pasaje entre los comentadores tardíos de la alquimia clásica y los árabes, problema ya abordado por Berthelot, ${ }^{4}$ ha merecido atención especial en la medida de la más adecuada valoración de la importancia de la ciencia árabe para el occidente latino. ${ }^{5}$

Todo este material componía un mosaico bastante variado de criterios, experiencias, fórmulas y conjuros (por ej. los de los libros herméticos cuya historia es más confusa y menos conocida). Pero en general podemos trazar un breve esquema de los principios alquimistas que eran generalmente aceptados en la primera mitad del s. XIII, tal como los conocieron los oxonienses.

\section{1 - La idea de "natura"}

Hasta el ingreso de la obra física de Aristóteles y la consolidación de los métodos de investigación, siguiendo la propuesta de Grosseteste y su escuela, la naturaleza es fundamentalmente objeto de contemplación, como reflejo de las eternas

1 Cf. Alistar C. Crombie, Histonia de la Ciencia de San Agustín a Galileo; I. La Ciencia en la Edad Media, ss. V al XIII, versión de José Bemia, Madrid, Alianza Editorial, 1974, p. 48.

2 Id. ibid. p. 50.

3 Cf. M. Plessner, "The Place of the Turba Philosophorum in the Development of Alchemy", Isis 45, n. 142, 1954: 331-338. Este autor discute la tesis de J. Riska, quien en su obra Turba Philosophorum, ein Beitrag zur Geschichte der Alchemie de 1931, admitiendo sus origenes árabes en los ss. IX ó X, sugiere que incluso podría ser de principios del s. XI y lo caracteriza como específicamente antigriego. Según Plessner, el modelo de Turba es Olimpodoro, aunque con diferencias: en el modelo griego los filósofos discutían a partir de comparaciones con los alquimistas mientras que en Turba toman parte de las discusiones alquimistas mismas; el griego está escrito como doxografia y Turba como diálogo etc.

4 M. Berthelot se ocupó del tema en Les origines de l'Alchimie (Paris, Georges Steinheil, 1885) dedicándole un parágrafo a la transmisión a los árabes (p. $205 \mathrm{ss)} \mathrm{destacando} \mathrm{la} \mathrm{importancia} \mathrm{de} \mathrm{Geber.}$

5 Después de Berthelot se ocuparon de este tema varios importantes historiadores del pensamiento árabe. Aldo Mieli presentó una historia unitaria para la alquimia y la química en función del tema de la teoria atómica (La science arabe et son rôle dans l'évolution scientifique mondiale, Leiden, E. J. Brill, 1938, p. 155 ss). Leacy O'Leary, en el contexto más amplio de la cultura de Medio Oriente, pone énfasis en la vía siria de recepción y transmisión de los textos clásicos (How Greek Science passed tothe Arabs, London, Routlege and Keagan Paul, 1964 p. 131 ss). Por otra parte, también ha destacado la importancia del medio heterodoxo cristiano (nestorianos y monofisistas) y la del medio budista en la transmisión de la antigua ciencia hindú (p. 110 ss.). 
ideas de la mente divina. ${ }^{6}$ La conjunción con las lecturas aristotélicas en un primer momento no modificó esta concepción: la astronomía conservó la idea de un determinismo astrológico (en cierta medida mágico) y lo mismo pasó con la transmutación de los metales. En la concepción alquimista medieval se unen dos principios explicativos del cosmos: el tradicional del esoterismo (que considera a la naturaleza como una unidad en proceso de perfección) y el aristotélico (según el hilemorfismo, los cuatro elementos pueden transformarse unos en otros porque sus formas son educidas de la infinita potencialidad de la materia). Esto explica que teorías alquimistas más concretas quieran estar basadas en las propiedades que el sistema aristotélico fija para los elementos y sus compuestos.

No obstante, también el aristotelismo pudo ser interpretado en contra de la alquimia. Hay un célebre paso en el De congelatione et conglutione de Avicena, en que se afirma la imposibilidad de transformar la especie de los metales ${ }^{7}$ por influencia del fijismo aristotélico. Raimundo Lullio, que escribe hacia el fin del s. XIII, utiliza el argumento del deseo natural de permanencia en el ser (al que, además, vincula con la voluntad divina que quiso darles determinados caracteres a las cosas naturales) para negar la pretensión de los alquimistas. Para que un metal se transforme, debe cambiar substancialmente: forma, materia y accidentes, pero esto va contra su deseo natural, que es más fuerte que el deseo del alquimista. ${ }^{8}$ Sin embargo, 20 años después de su muerte, figuras combinatorias análogas a las suyas fueron utilizadas por un alquimista catalán autor del Testamento que toda la tradición atribuye a Raimundo. En esta obra, cuya importancia es decisiva en la historia de la alquimia latina, al tratar la preparación del elixir, el alquimista intenta una "filosofía alquímica" en la cual los temas y conceptos de la filosofía natural escolástica (de base aristotélica) son reinterpretados a la luz del opus alquímico. Algo semejante sucede con el Liber de secretis naturae seu de quinta essentia, atribuído a Lullio porque también usa sus figuras combinatorias e incluso trae una exposición destinada a justificar la atribución a ese autor. El éxito del recurso es evidente: esa imagen de Raimundo alquimista es recepcionada por los primeros renacentistas y la alquimia queda incluida en la visión lulliana de las ciencias hasta el s. XVII, y

6 Cf. Tulio Gregory, "L'idea di natura nella filosofia medievale prima dell'ingresso della Fisica di Aristotele", La Filosofia della natura nel Medioevo, Atti del 3. Congr. Intem. di Filosofia Medioevale, Milano, 1964. p. 27.

7 Cf. Michaela Pereira "L'Enciclopedia Lulliana e l'Alchimia", América 92, São Paulo, 1992, p. 179.

8 Cf. Armando Llinarés, "L'idée de nature et la condamnation de l'Alquimie d'apres le Livre des Merveilles de Raymond Lulle", Filosofia della natura nel Medioevo, cit, p. 536-451. El cap. 35 del Libro VI de la obra lulliana trata de la alquimia, condenando sus pretensiones transformistas. En otra obra, El árbol de la ciencia, I, VI, habla de las transmutaciones como una de las formas o causas de la generación, pero no se refiere a los procesos alquímicos, que implican cambio sustancial (según Lullio, cambio inclusive de la materia, lo que no sucede, por ej. en la transmutación del pan en came). No obstante muchas obras alquimistas le fueron atribuidas poco después de su muerte. Carreras y Artau y actualmente García Font piensan que la obra alquímica atribuida a Lullio tuvo origen en ambientes espirituales, pero Thorndike, observando su heterogeneidad, propone que hubo un núcleo acrecentado. Michela Pereira acepta esta idea y desarrolla esta posible conexión histórica , en "Alchimia lulliana: aspetti e problemi del 'corpus' di opere alchemiche attribuite a Raimondo Lullo (XIV-XVII sec.), Atti del Convegno Int. Ramon Lull, 1989, Annali dell'Istituto Universitario Orientale, Sezione Romanza, XXXIV, 1. Napoli, 1992, p. 117-130 (lo mencionado en pp. 117-118). 
fortalecida con el peso de su prestigio. Podemos concluir, pues, que las teorias filosóficas o las concepciones cosmológicas corrientes en el s. XIII podían servir tanto de fundamento a las prácticas alquimistas, como para su condenación. Esta ambigüedad sólo queda superada, en la práctica, con la adopción sistemática de un nuevo método científico que, entre otros aspectos, es atomístico y cuantitivo; por eso la ciencia del s. XVII desplaza definitivamente a la alquimia. ${ }^{9}$

\section{2 - Los metales}

En la historia de la ciencia hay numerosas tablas y listas de metales, así como de su ubicación dentro de los minerales en general. Una de las más conocidas es la de Geber (oro, plata, plomo, zinc, cobre, hierro y "hierro chino"); en general los primeros miembros son siempre aceptados, los últimos varían, y se piensa que eran aleaciones, puestos en la tabla para completar el número mágico de siete. Además debemos agregar una larga lista de piedras que eran consideradas sagradas o mágicas desde los egipcios, como el zafiro, la esmeralda y otros, por cuya perfección eran asimiladas a los metales. ${ }^{10}$ Por otra parte están los "espíritus" materiales que entran en el proceso, fundamentalmente el mercurio y el azufre (sulfuros), al que Rhazes aade un tercer principio, el de la sal. El sulfuro representa el espiritu, el mercurio el alma y la sal el cuerpo (como principio de cristalización). De este modo la experimentación se hacía más factible. Seguramente en los "laboratorios" occidentales de los Ss. XII y XIII se adelantó más, en cuanto a los aspectos experimentales, que en los diez siglos anteriores, y ello debido al impulso dado por los últimos científicos árabes.

\section{3 - Las teorías alquimistas}

Desde sus más remotos orígenes, las teorías alquimistas estuvieron ligadas a una concepción filosófica, y por ello usaban conceptos tomados de Platón, Aristóteles y otros célebres filósofos griegos. Pero más concretamente, aquí nos interesan dos aspectos: la gradación perfectiva de los metales y su forma de reducción. Según lo primero, hay una escala jerárquica entre los metales, cuyo primer lugar está ocupado por el oro, y del cual los demás no son sino sucesivos grados de imperfección. Y esto se explica, dicen, porque la materia primera de ellos es la misma. Por tanto - segundo aspecto - es necesario reducir los metales, según la propiedad que les es esencial, para quitarles su "escoria", transformándolos en oro puro. Esto supone un proceso a la vez mágico y "científico". Científico, por cuanto se aprovechan cualidades objetivas y reales de los cuerpos, conforme a leyes estables de transformación. El que esas leyes fueran, entre los alquimistas, vagas y míticas, no obsta a este aspecto que permitió al menos un progreso en lo relativo al instrumental de experimentación. Si bien hay que aceptar que la alquimia como tal no es la prehistoria de la química, sino que ésta, en la modernidad, se constituye con otros

9 Esta es la tesis desarrollada por Ana M. Alfonso Goldfarb, en Da alquimia a química. Um estudo sobre a passagem do pensamento magico-vitalista ao mecanicismo, São Paulo, Nova Stella-EDUSP, 1987.

10

Cf. M. Berthelot, Les origines de l'Alchimie cit, p. 218 ss. 
supuestos teóricos, no podemos negar que los aspectos prácticos de la experimentación fueron provistos por los alquimistas. Pero a la vez en las prácticas alquimistas se mezclaba la magia, porque se daba importancia a fórmulas secretas y conjuros, es decir, a la intervención de fuerzas ocultas que el ałquimista no conocía en sí mismas y que sólo podía "dominar" por fórmulas arcanas.

Esta apelación a las fuerzas ocultas vincula a la alquimia con la magia, vinculación que sin duda existió aunque no es muy clara. En primer lugar, es necesario advertir que el concepto de "magia" no es unívoco y hay muchas prácticas y saberes medievales que pueden ser llamados mágicos, pero no en el mismo sentido. En segundo lugar, tampoco la valoración de los diversos tipos de magia es igual ni constante a lo largo de los siglos medievales. Kieckhefer ${ }^{11}$ propone distinguir en primer lugar entre la "magia tradicional común" y la "magia especializada". La primera comprende seis prácticas: la medicina mágica (añadir observancia de tabúes determinados a la administración del medicamento), los hechizos (fórmulas verbales), el uso de amuletos y talismanes, la brujería (usar objetos con técnicas mágicas, que puede ser magia blanca o negra), la adivinación y la realización de trucos (como forma de diversión). La "magia especializada" requiere cierto profesionalismo y comprende la astrología, la alquimia, la magia astral y la necromancia. Aunque la magia en este sentido especializado habia sufrido fuertes suspecciones desde el s. V, hacia el s. XII en los círculos cultos de occidente se comenzó a valorar positivamente, quizá por influencia de las traducciones del árabe, que la presentaban con respaldo aristotélico. Sin embargo las relaciones entre la alquimia, la magia medieval en sus dos formas y el hermetismo clásico no están claras. Es evidente que el Corpus hermeticum helenístico tiene pocos vínculos definidos con la alquimia tal como se fue elaborando en el ambiente árabe y se recepcionó en la latinidad entre los ss. XII y XIII. Por eso algunos investigadores han concluido en la existencia de una antiquísima corriente hermética "popular" que habria influído más y más directamente en los estudios de la naturaleza, tanto medievales como renacentistas. Se cita como ejemplo de esto el Libro del tesoro de Alejandro escrito en el mundo árabe entre los Ss. IX y X, que representa bien esta fase de la alquimia o "hermética popular" en su versión árabe, que fue la vía de acceso a occidente. ${ }^{12}$ En esta línea estaría el famoso Picatrix, obra que se supone escrita por un árabe andaluz del s. XII. ${ }^{13}$

Tal era, en grandes rasgos, el estado de la cuestión a principios del s. XIII, cuando Grosseteste comienza su labor intelectual, que culmina en la propuesta de un nuevo método científico. Es interesante analizar cuál es el lugar que la alquimia podía tener en el nuevo sistema. Para ello tocaremos dos puntos: en primer lugar,

11 Richard Kieckhefer, Magic in the Middle Ages, Cambridge University Press, 1989.

12 Ana María Alfonso Goldfarb, "A hermética e o complexo mosaico dos saberes árabes medievais sobre a natureza do Livro do Tesouro de Alejandro", V Semináno Nacional de Históna da Ciência e da Tecnologia, Ouro Preto, 1995, p. 4-5.

13 M. Villegas, editor de la obra según un manuscrito árabe del s. XV ó XVI, la supone escrita por el Pseudo Abul-Casim-Maslama-Ben Ahmad el Madrileño. Fundamentalmente es una obra de magia astrológica que algunos investigadores actuales consideran fuente del hermetismo renacentista (cf. Picatrix: el fin del sabio y el mejor de los dos medios para avanzar, Madrid, Ed. Nacional, 1982, "Introducción"). 
analizaremos los escasos textos del Lincolniense sobre transmutacion de metales, de donde intentaremos deducir, en consonancia con el resto de sus teorías, su posición sobre la alquimia. Luego veremos rápidamente cómo interpretaron su enseanza algunos medievales inmediatos. La historia de la alquimia en el s. XIV, aunque interesante, queda fuera de nuestros parámetros temporales en este trabajo.

\section{Los textos del lincolniense sobre transmutación de los metales}

La obra científica de Grosseteste abarca los años 1215-1235 aproximadamente y suele dividirse en tres períodos, el primero de los cuales - hasta 1225 - no nos aporta sino muy fragmentariamente ideas acerca de su método científico. Las obras en que lo propone y lo aplica pertenecen a los otros dos. El De artibus liberalibus, única obra en que trata temas relacionados con la alquimia, pertenece al primer periodo ${ }^{14}$ Dos ideas, que luego son retomadas y perfeccionadas en su método, pueden rastrearse aquí. En primer lugar, la idea del mundo como reflejo de las ideas divinas, tesis tradicional del agustinismo platonizante. ${ }^{15}$ Este ejemplarismo fundamenta la continuidad y seguridad de las leyes naturales, más allá de la contingencia de sus objetos, en cuanto serían expresión del orden querido por Dios para la naturaleza, y como tal, inmutable y universal. La matemática, como ciencia de las relaciones y los números, es la más alta expresión, a nivel humano, de la captación de esta estructura legal. De allí que, en segundo lugar, la matemática sea colocada por Grosseteste en la cúspide de las artes liberales, incluyendo a la astronomía y la astrología (ésta, a su vez, incluída en la anterior). Más abajo en la escala jerárquica, como corresponde a la contingencia de sus objetos, está el complejo de la filosofía (ciencia) natural, que incluye agricultura, alquimia, medicina y música, conjunto que luego Bacon retomará y ampliará en el sistema propuesto en el Opus Majus. Grosseteste admite influencias astrológicas en medicina y alquimia ${ }^{16}$ lo cual es explicable por esta subalternación propuesta, que aún no está desarrollada como lo hará más adelante, en sus comentarios a Aristóteles pero que ya se preanuncia. ${ }^{17}$

Grosseteste acepta la idea tradicional de que los metales no áureos son degradaciones del más perfecto, y de que no son simples sino compuestos, con mayor o

14 Cf. Ludwig Baur, Die philosophischen Werke des Robert Grosseteste zum Erstenmal vollstandig im kritischer Ausgabe, Münster, 1912, Prolegomena, p. 55 ss. Sobre cronología de la vida y obras de Grosseteste v. Richard C. Dales, "Robert Grosseteste's scientific works", Isis 52, 1961: 381-402, y tabla cronológica editada en Robert Grosseteste, scholar and Bishop, Oxford, At the Clarendon Press, 1961, pp. 251-252. Sigue aqui el Lincolniense una vieja tradición que se remonta hasta las obras homónimas de Marciano Capella (s. V) y Boecio (s. VI).

Cf. Servus Gieben, "Traces of God in nature according to Robert Grosseteste", Franciscan Studies 24, 1964: 144-158.

16 Cfr. Lynn Thorndike, "The true Bacon", American Historical Review 21, 1916, p. 445.

17 No tratamos la Summa por considerarla espúrea; no obstante, toca ligeramente estos temas. El autor divide el saber en tres disciplinas: Teologia, Filosofia y Ciencia, y esta en especulativa y experimental (I, II, ed. Baur, Werke... cit, p. 284-285). Cuando se refiere a la experiencia y el saber fundado en ella, afirma que es fundamento de los asertos y predicciones astrológicas (XXX, 2 y XV, 30, ed. Baur p. 627 y 588), idea que se repite en ocasión del tratamiento de los Cometas (Baur, 586), y admite que las virtudes ocultas de los astros influyen en las transmutaciones (XIX, 6, 7; ed. Baur p. 6334). 
menor proporción de elementos imperfectos. Por lo tanto, la transmutación de metales en sí es posible:

(1) "Los restantes metales no se diferencian del oro sino según la impureza de la materia o desproporción de complexión. Por lo cual transmutarlos es limpiar la impureza y añadirles la substancia expurgada y asimilada del sol en potencia y operación, para reducir la desigualdad."

De artibus liberalibus, Baur, Werke, p. $6 .{ }^{18}$

Nos dá aquí Grosseteste su concepción sobre el arte alquimista: consiste en separar los elementos imperfectos de los compuestos no áureos, cuya desproporcionada cantidad es causa de la imperfección del metal. La substancia asi purificada se "asimila" al sol, es decir, el astro más perfecto, en cuanto hay una relación entre planetas y metales, conforme la tradición tanto alquimista como astrológica. Y así como el sol, por su perfección, tiene máxima potencia agente con relación a los cuerpos sublunares, y por eso su causalidad es universal con respecto a las generaciones de ciertas substancias terrestres, así también el metal solar, el oro, tendrá máxima potencia operante sobre realidades sublunares más imperfectas. De ahí la virtud curativa y transformadora atribuída a la piedra filosofal.

Otro texto de similares características, expresa la misma idea de la degradación metalúrgica: la naturaleza tiende a lo perfecto, los metales por sí tienden al oro como a su perfección. Es este principio ontológico el que justifica la verosimilitud y probabilidad de las prácticas alquímicas:

(2) "Pues todos los metales, por tendencia natural, deberían ser oro, del cual no se diferencian sino como lo imperfecto de lo perfecto"

De artibus liberalibus, Baur, Werke, p. 5.

Grosseteste no fue un alquimista, y es evidente que tampoco conocía en detalle esas tácnicas; sus observaciones son generales y apuntan más bien a otros aspectos del problema de la transmutación. En esta obra, única referencia a la alquimia, como vemos, la acepta en cuanto a sus fundamentos científico-filosóficos, que acabo de exponer. La cuestión subsiguiente es la metodología concreta que efectivamente conduzca a la transmutación. Esto, que para los alquimistas prácticos era problema fáctico, para Grosseteste, interesado en una fundamentación teórica del conocimiento científico, es esencial. En efecto, para él hay diversos niveles de "ciencias" según el ordo essendi; en el escalón más bajo (las "ciencias" en sentido lato e impreciso) ubica la mera descripción de los fenómenos contingentes, mientras que la ciencia en sentido propio tiene por objeto los fenómenos naturales, que suceden siempre o muy frecuentemente de la misma manera, conforme a la caracterización ya dada por Aristóteles; más alta aún, la ciencia magis proprie implica la comprehensión de la verdad inmutable de las legalidades, y por último tenemos la metafísica: su objeto es lo inmutable absoluto. ${ }^{19}$ Ahora bien ¿a cuál de estos grados debemos referir los conocimientos alquímicos?. Obviamente descartamos el último, tampoco el primero, pues sólo sería ciencia en sentido impropio. Te-

18 Citamos por la edición de Baur, cf. nota 6.

19 Cf. Robert J. Palma, "Grosseteste's ordering of scientia". The new Scholasticism 50, n. 4, 1976, p. 452 ss. 
niendo en cuenta que se trata de fenómenos de experimentación y no de deducción, su lugar sería el segundo grado, ciencia en sentido propio. ${ }^{20}$ En general, este es el grado quia de explicación y por lo tanto, requiere una metodología de la investigación física.

Si esto es así, tenemos necesidad de dos momentos en el estudio de la transmutación: la descripción pura y la explicación fáctica, es decir, a nivel de las leyes inmediatas de la física. Según los textos que poseemos, parece que el Lincolniense aceptaba como válidas ciertas experiencias que, si no habían producido oro, se acercarían a la efectividad del proceso, en cuanto producían "depuración" del mineral base. Pero evidentemente le interesaba más el principio explicativo, que él halla en la relación - ya clásica en la escuela alquímica - entre los metales sublunares y las propiedades de los cuerpos celestes.

En esta etapa de su carrera intelectual, Grosseteste acepta la posibilidad de influencias astrales, y también el paralelismo que justifica la inferencia a partir de las propiedades atribuídas a las esferas superiores, tema del cual me ocupé en otra oportunidad. ${ }^{21}$ La concepción alquimista reflejada en De artibus liberalibus está totalmente ligada a la astrología: así como hay una gradación de perfecciones entre los astros, la hay entre los metales; la conjunción astral, pues, determinará la formación de los diferentes metales en el mundo sublunar. Esto ha sido así en el origen natural, y el hombre debe, de algún modo, repetir imitativamente este proceso:

(3) "En la preparación de la piedra filosofal que produce la combinación de los minerales, no es menos necesaria la elección del tiempo [...]. Esta substancia [áurea] no se prepara a cualquier hora, sino cuando el sol tiene su exaltación en Libra, sin mala aspectación, porque entonces está en su máxima fortaleza, y así atrae de esa materia la substancia semejante a sí, la cual no puede pasar de la potencia al acto sino en ciertas horas".

De artibus liberalibus, Baur, Werke, p. 5-6.

No hay más referencias metodológicas concretas, pero podemos inferir con seguridad el principio: imitatio naturae. Las limitaciones a este proceder serán, en todo caso, fácticas y relativas a la disponibilidad instrumental, pero no ofrecen problemas teóricos.

En cambio el paso siguiente, es decir, la fundamentación de la metodología experimental en la estructura y modo de formación de las naturas sublunares por relación a las celestes, no está tan claro. Este paralelismo es más bien una intuición aproximativa que una verdadera proposición teórica suficientemente precisa como para derivar conclusiones unívocas y significativas. Para que estas formulaciones alcancen la categoría de ciencia propia (aunque quia) es necesario establecer relaciones biunívocas entre elementos componentes o coadyuvantes a la formación y transmutación. Esto es lo que intenta Grosseteste, en el texto más extenso sobre formación de los metales básicos, dejando de lado toda la literatura esotérica con que los tratados alquimistas solían presentarla. Las variables que toma en cuenta el Lincolniense - es decir, las que según sus principios cientificos tienen

20 Esto se refuerza considerando que la scientia magis propria implica el uso de la matemática (por ej. en relación a la óptica).

21 "Robert Grosseteste: Astronomie et Astrologie au début du XIIème siecle", Abstracts, 6th. Intemational Congress of Logic, Methodology and Philosophy of Science, Hannover, 1979, Sections 13-14, p. 86-90. 
significación explicativa a nivel de la ciencia empírica - son: propiedades de los planetas (cálido-seco-frio-húmedo) y sus combinaciones; naturaleza del mineral base sublunar. El mercurio y el sulfuro son constantes. El resultado es una "cocción" (mixtión) de diferentes grados, cuyo resultado óptimo es el oro, y en los restantes casos, por exceso o defecto, los demás metales, hasta completar el número de siete, siendo correlativos a los planetas.

El siguiente párrafo es el resumen de esta hipótesis alquímica básica, despojada de elementos y referencias mágicas; no es, como se aprecia, nada original. En el contexto metodológico de Grosseteste, tiene la importancia de sealar el límite de la hipótesis científica: si el proceso natural se ha producido así, su reproducción artificial humana debe producir iguales o semejantes resultados.

(4) "Cuando la potencia solar mueve al vapor sulfúreo mezclándose con el mercurio, y se cocina con cocción temperada, se produce el oro. En cambio, cuando el calor solar se conjuga con la frialdad de la luna, de tal modo que la cocción de esos elementos es escasa, se produce la plata. Pero si el calor solar se conjuga con la frialdad de Satumo, como él mismo es de naturaleza terrestre, el humo sulfúreo se mueve junto con la impureza terrestre y se mezcla con el mercurio, cocinándose poco; entonces aparece el plomo. Y si el calor solar se mezcla con el calor y la humedad de Júpiter, la cocción será escasa y aparecerá el estao. Cuando el calor solar se aade al calor sobreabundante y la sequedad de Marte, el sulfuro pesado y el mercurio pesado se cocerán en demasia, y se extraerá el hierro. El calor de Venus con el calor del Sol produce algo semejante con una cocción más temperada, pero menos que la producida por Marte. La potencia de Mercurio mezclando el agua viscosa con el vapor sulfúreo produce el mercurio."

De artibus liberalibus, Baur, Werke, p. 6.

Esta nómina de metales, como casi todas las que enumeran siete por motivos cabalísticos o para completar el número de planetas, no es uniforme a partir del quinto. No obstante esto en nuestro caso tiene poca importancia, ya que es un pasaje referido y no un punto de partida de investigaciones ni experiencias alquimistas.

Llegados aquí, y puesto que no tenemos más textos posteriores del Lincolniense, podemos preguntarnos cuál fue su posición definitiva al respecto. La cuestión guarda interés tanto desde el punto de vista de la metodología científica, como de la historia de los intentos alquimistas. El silencio ulterior de por sí no es significativo: Grosseteste no se interesó personalmente en estas largas y complicadas experiencias; es natural que no tuviera nada más que decir. No obstante el margen hipotético de nuestras deducciones históricas, estamos al menos en condiciones de asegurar algunos extremos: en primer lugar, Grosseteste ha rechazado todos los aspectos mágicos que pudieran existir en las prácticas esotéricas, tanto astrológicas como alquimistas, por motivos religiosos. Una parte de las experiencias, justamente aquellas que hacian uso esencial de fórmulas y conjuros, quedaba fuera de su aceptación. Por el otro extremo, podemos constatar que Grosseteste no sólo no condenó ni negó la posibilidad de la transmutación, sino que incluso elaboró las bases científicas de su posibilidad. En esto se mostraba como un espíritu culto de su tiempo, manteniendo una prudente reserva sobre los hechos, sin aceptar ni negar nada acriticamente. Reducida la labor alquimista a la experimentación concreta sobre la base de postulados tan simplificados, el resultado no podía ser sino negativo, desde una perspectiva cientifica moderna. Grosseteste quizá albergó dudas sobre la cientificidad de esta disciplina, y tal vez por ello no la incluyó entre las cien- 

la Physica, obra de madurez.

\section{La transmutación y la metodología científica oxoniense}

La importancia de la propuesta metodológica del Lincolniense fue irreversible; sus criterios de matematización, verificación empírica y subordinación científica presidieron la creación de sus sucesores. Si bien la alquimia no entró en la temática del último Grosseteste, sí preocupó mucho a uno de sus discípulos, Roger Bacon, hasta el punto de considerárselo introductor de la alquimia en Europa. ${ }^{22}$ No vamos a entrar aquí en el problema histórico de sus obras esotéricas y sus relaciones con los alquimistas ${ }^{23}$ porque nos interesan sólo los aspectos de encuadre metodológico. Es justamente Bacon quien ha hecho el más profundo esfuerzo por explicitar la metodología de la alquimia como ciencia de los metales y en darle un lugar en su cuadro general científico. En sus obras, Roger postula una teoría de la ciencia como descubrimiento de la realidad y de la verdad. Se llega a los universales (explicación causal) por inducción y experimento, y se usa la matemática para explicar la conexión de los eventos. ${ }^{24}$

La ciencia más perfecta es la experimental, cuya primacía queda asegurada por dos principios metafísicos ya presentes en Grosseteste: la uniformidad de la naturaleza y la economí; no es, por tanto, mera descripción fenoménica, explica realmente la naturaleza. Esta ciencia se sirve de "invenciones prácticas", es decir, experimentos para investigar la naturaleza. En este punto, su admiración 0 ingenuidad le hacen aceptar aun pretendidas ciencias, con elementos mágicos, y quizá por ello sufrió en parte la condenación de $1277,{ }^{25}$ ya que sin duda las "doctrinas peligrosas" mentadas son la astrología y la magia.

En cualquier caso, la segunda mitad del s. XIII oxoniense (y europeo) marca un hito en el desarrollo de la ciencia experimental según los principios ya esboza-

22 Bacon habría estudiado el Secreta secretorum del pseudo Aristóteles, del que hizo un comentario en De retardatione, y como probablemente pretendia hacer uso de la alquimia en medicina, estudió el De Anima del Pseudo Avicena, haciendo un sumario que se halla disperso en Speculum Secretorum, Breve breviarium y Tractatum verborum, publicados póstumamente en 1603 en Frankfurt con el título Sanioris medicinae. A pesar de su disparidad suelen considerarse auténticos. Tomó de Avicena la idea de que los metales se constituyen por mezclas de azufre y mercurio en diversas proporciones, que también vimos en Grosseteste, siendo el oro la proporción más perfecta (Cf. A. Alfonso Goldfarb, ob. cit. p. 130).

23 Sobre este punto v. M. M. Pattison Muir, "R. Bacon, his relations to Alchemy and Chemistry" Essays, Oxford, 1914, 235-320; discute la posición de Berthelot sobre el encuadre histórico del pensamiento baconiano en alquimia, y concretamente considera dudoso el Speculus alchimiae, comparándolo con pasajes paralelos de la Epistola y del Opus Tertium. Por otra parte, el Speculum ha sido atribuído repetidamente a Alberto Magno.

24 Cf. Thorndike, "The true Bacon" cit. p. 477.

25 Cf. Chartularium Universitatis Panisiensis, p. 543-558. Aunque se ocupa de la magia y la astrología, ellas no son el objetivo principal de esta condenación; al parecer las censuras subsiguientes tampoco lograron el efecto buscado. Varios investigadores actuales (por ej. F. Yepes, A. J. Festugière, D. Ealker, E. Garin y otros) elaboraron una hipótesis sobre el papel de la magia en el desarrollo de la cultura científica modema asumiendo una línea directa de trasmisión desde los escritos antiguos atribuidos a Hermes hasta el s. XVI, pasando por los árabes y los latinos medievales llegando a Bruno y Marsilio Ficino (cf. Rafael Martinez, "Giordano Bruno y la tradición hermética", Mathesis 1, n. 1, 1985: 635-443). 
dos de Grosseteste, y Bacon no es un caso aislado. Thorndike afirma que en la idea baconiana de la ciencia experimentál y en la narración de experiencias, han tenido influencia los alquimistas. ${ }^{26}$ Una muestra de ello sería la común referencia a las "potencias ocultas" que no son deducibles ni experimentales; no sólo Bacon habló de ellas, sino también Pedro de Albano, Arnaldo de Vilanova, Tomás de Aquino, Alberto Magno, etc. Thorndike ve otra conexión entre Bacon y los alquimistas en su propensión al "experimento fantástico" (o experiencia puramente mental y por tanto a veces irrealizable).

Está claro, por lo menos, que la aceptación de estas fuerzas ocultas, aunque tenga relaciones con la magia en cuanto a sus implicancias o formas de manipuleo, en Bacon se encuadra en un marco científico que pretende hallar una conexión real entre la experiencia y el principio mágico. Por eso el alquimista no es el principal artífice del experimento, sino el científico, es decir, el que fija los principios y legalidades teóricas de las prácticas experimentales:

(5) "El alquimista prepara esto, pero el cientifico lo indica al alquimista, y le ensea su uso, asi como el navegante ensea al constructor a fabricar la nave y conoce su uso".

Opera hactenus inedita, ed. Brewer, p. $376 \mathrm{ss}^{27}$

La tesis de Thorndike, en el sentido de que en el origen de los experimentos haya un recurso a la magia y que la ciencia, al principio puramente especulativa, se haya inclinado hacia la magia a través del método experimental (la idea-nexo sería la de "fuerza oculta") debe ser matizada, en cuanto en Bacon al menos: está claro que ciencia experimental y alquimia (que incluiría los elementos mágicos) no son la misma cosa. Pero tampoco son dos líneas paralelas, sino que, metodológicamente, la segunda se funda en la primera. Esta ciencia experimental es una metodología general de las ciencias descriptivas del universo, y como tal, supuesto necesario de todas las especialidades.

Por otra parte, tampoco la alquimia puede equipararse sin más a la magia. El mismo Bacon, que en algún tiempo se interesó en prácticas mágicas, se decepcionó e incluso escribió un tratado en su contra, la Epistola de secretis operibus. No obstante, en algunos pasajes admite que de la magia se obtengan algunas verdades. Según Thorndike esto se debe a su admisión de la posibilidad de una ciencia oculta en la medida en que aceptaba los poderes ocultos de las cosas. ${ }^{28}$

La posición de Bacon puede considerarse paradigmática y sus dificultades son semejantes a las que enfrentaron otros oxonienses y europeos a la hora de dar a la alquimia un estatuto científico. No obstante este esfuerzo, la estructura del corpus alquimista del como se había recibido de la tradición, no resistió a la aplicación de principios metodológicos modernos. Ello explica su eclipse posterior entre las disciplinas que alcanzaron nivel científico.

26 Cf. Thomdike, "R. Bacon and experimental method in the Middle Ages", Philosophical Review, 23, 1914, p. 280 ss.

27 Cf. Dorothea Walley Singer, "The alchemical writtings of Roger Bacon", Speculum 2, 1934: 80-86; textos en Fr. Rogeri Bacon Opera Quaedam inedita, edited by J. S. Brewer, M. A. Originally published 1859 by Her Majesty's stationery Office, London, Kraus Reprint LRD, 1965. 


\section{TEXTOS CITADOS}

(1) "Reliqua [metalla] vero ab auro non differunt, nisi secundum immunditiam materiae aut complexionis inaequalitatem. Quapropter transmutare ista est immunditias abstergere et mundificatis substantiam apponere assimilatam soli in virtute et operatione, quas ipsa reducit ab inaequalitate." De artibus liberalibus, Baur, Werke, p. 6.

(2) "Omnia enim metalla de intentione naturae aurum esse debuerunt: nec differunt ab auro nisi sicut imperfectum a perfecto."

De artibus liberalibus, Baur, Werke, p. 5.

(3) "In praeparatione vero lapidis, quo metallorum fit transmutatio, non minus necessaria est horarum electio (...) Haec substantiam [auream] non qualibetcumque hora praeparatur, sed cum fuerirt sol in exaltatione librae ab aspectu malorum; quae tunc est in fortitudine et extrabit in materia huiusmnodi substantiae virtutem sibi assimilitam, quam non potest nisi in certis horis de potentia ad actum producere."

De artibus liberalibus, Baur, Werke, p. 5-6.

(4) Cum enim virtus solis movet fumus sulphureum mundum commiscens illum cum argento vivo et decoquit ipsum decoctione temperata, fit aurum. Cum vero calore solis complectitur frigiditas lunae, ita quod parva sit praedictorum decoctio, nascitur argentum. Sed si calore solis commisceatur frigiditas Saturni, quia ipse est terreus, movetur fumus sulphureus cum immnunditia terrestri et commiscetur cum argento vivo et mundo et decoquitur decoctione parva, nascitur plumbum. Si autem calore solis commisceatur calor et humiditas Jovis, movetur fumus sulphureum ingressione sua et commiscetur cum argento vivo et mundo, sed propter humiditatem solis admiscetur calor suplerfluus et siccitas Martis, sulphur grossum cum argento vivo grosso, superflue excoquitur et ferrum extrahitur. Calor autem veneris cum calore solis proprie dicta decoquens plus decoctione temperata, minus tamen quam sit decoctio excussa per Mars lotionem excutit. Virtus vero Mercurii cum aque viscosa sulphureum commiscens vivum efficit argentum."

De artibus liberalibus, Baur, Werke, p. 6.

(5) "Hoc alkimista preparat, sed experimentator imperat hoc alkimiste, et novit uti eo, sicut navigator carpentatori de navis fabricatione et ea scit uti".

Opera hactenus inedita, ed. Brewer, p. 376. 